\title{
Loạt bài báo mô tả dữ liệu về các vấn đề xã hội trong mùa dịch COVID-19 từ Việt Nam
}

\author{
Nguyễn Thanh Nhàn \\ AI for Social Data Lab \\ Hà Nội, 08-08-2020
}

Trong đại dịch COVID-19, song hành cùng với sự nỗ lực miệt mài của các bác sĩ ở đầu chiến tuyến thì các nhà nghiên cứu cũng đóng góp những quan sát và đánh giá sự thay đổi trong đời sống xã hội. Không chỉ là những nghiên cứu gốc, nhiều nhà nghiên cứu còn đã công bố mở các bộ dữ liệu, chung tay đóng góp tài nguyên khoa học.

Khoa học và Phát triển (08-08-2020; https://khoahocphattrien.vn/khoa-hoc/loatbai-bao-mo-ta-du-lieu-ve-cac-van-de-xa-hoi-trong-mua-dich-covid19-tu-vietnam/2020080706144617p1c160.htm) — Đại dịch Covid nổ ra đã kéo theo hàng loạt ảnh hưởng đến nhiều đời sống xã hội. Tại Việt Nam, ngay trong thời điểm dịch bệnh mới bùng phát vào đầu tháng 3 , các nhóm nghiên cứu khoa học xã hội đã nhanh chóng công bố một số phân tích đầu tiên về tình hình chống dịch [1], hay đánh giá nhanh nhận thức về mức độ nguy hiểm của người dân [2].

Không chỉ đóng góp các nghiên cứu gốc, các nhà khoa học Việt Nam còn công bố các bộ dữ liệu về các vấn đề xã hội trong đại dịch COVID-19 dưới dạng các bài báo mô tả dữ liệu (thường gọi là Data Descriptors hay Data Article). Đây là một dạng bài báo khoa học mới, nhằm mục đích chia sẻ thông tin chi tiết về một bộ dữ liệu, bao gồm cả phương pháp thu thập và xử lý. Các tạp chí công bố dạng bài này đều là các tạp chí mới và mở hoàn toàn. Họ ủng hộ việc chia sẻ và tái sử dụng các bộ dữ liệu, tạo ra sự minh bạch trong khoa học. Scientific $\underline{\text { Data }}$ [2019 JIF = 5.541; 2019 CiteScore = 8.4], Data [ESCl; 2019 CiteScore = 2.1], Data in Brief [ $[\mathrm{ESCl} ; 2019$ CiteScore = 1.5] là một số các tạp chí về chia sẻ dữ liệu đáng chú ý.

Bảng dưới đây xin tổng hợp các bộ dữ liệu về các vấn đề xã hội tại Việt Nam trong đại dịch COVID-19 mà tác giả đã tìm thấy dựa trên dữ liệu SSHPA (URL: https://sshpa.com/): 
Data for understanding Kinh tế xã hội, sự chú ý của truyền thông 319 người Việt Nam [3] the risk perception of và nhận thức về rủi ro của COVID-19 tại độ tuổi từ 15-47.

COVID-19 from Việt Nam

Vietnamese sample

Impact of the COVID-19 Hành vi, nhận thức, sự nhạy cảm của sinh 440 sinh viên đại [4] pandemic

perceptions on viên đối với khủng hoảng COVID-19 học.

behaviors of un

students in Vietnam

Dataset of ex-pat Ý định, nhận thức và mức độ gắn bó của 307 giáo viên thuộc [5] teachers in Southeast giáo viên nhập cư tại các nước Đông Nam các nước Đông Asia's intention to leave Á Nam Á.

due to the COVID-19

pandemic

Dataset of Vietnamese Quản lý giáo dục và sự hài lòng của giáo 294 giảng viên Việt [6] teachers' perspectives viên trong đại dịch COVID-19.

and perceived support

during the COVID-19

pandemic

Dataset of Vietnamese Thói quen học tập của học sinh Việt Nam 460 bạn học sinh từ [7] student's learning habits trong thời gian học online do virus COVID- lớp 6 đến lớp 12. during COVID-19 19

Impact of female Ý định và mục tiêu sử dụng công cụ hỗ trợ 254 sinh viên nữ tại [8] students' perceptions học tập online trong đại dịch COVID-19 Việt Nam. on behavioral intention

to use video

conferencing tools in

COVID-19: Data of

Vietnam

Toàn bộ các bài báo đều được công bố trên tạp chí Data in Brief của nhà xuất bản Elsevier. Điều này có thể xuất phát từ chính sách bình duyệt nhanh liên quan tới các bài viết về COVID-19 mà tạp chí áp dụng. Bên cạnh đó, vì loại bài báo này mô tả cấu trúc logic và phương pháp thu thập dữ liệu nên quá trình bình duyệt cũng có thể khác so với một bài công bố kết quả nghiên cứu gốc. Đối với tạp chí Data in Brief, họ cũng nêu rõ quá trình phản biện của tạp chí tập trung vào tính minh bạch của dữ liệu, với các tiêu chí cụ thể như:

- Phần mô tả dữ liệu có hợp lý không? 
- Tác giả có giải thích rõ tính khả dụng của bộ dữ liệu với cộng đồng không?

- Quá trình thu thập dữ liệu có đảm bảo không?

- Định dạng dữ liệu có đủ tiêu chuẩn (dễ dàng tái sử dụng) không?

- Dữ liệu có được báo cáo đầy đủ không?

Có đến $5 / 6$ bộ dữ liệu điều tra các đối tượng trong ngành giáo dục như sinh viên hay giáo viên [4-8]. Giáo viên và học sinh là những người phải thay đổi và thích nghi với cách ly xã hội rõ nét nhất. Vì không được học tập trung tại trường nên họ buộc phải chuyển sang hình thức học online. Do đó, giáo viên, học sinh, thậm chí cả các bậc phụ huynh đều phải làm quen với hình thức này nhưng vẫn còn nhiều bỡ ngỡ khi phát sinh nhiều khó khăn về mặt công nghệ hay cơ sở vật chất. Tuy nhiên đây cũng là cơ hội giúp các bạn học sinh sinh viên tiếp cận với công nghệ mới, hình thành thói quen sắp xếp thời gian biểu và tăng cường sự tham gia của phụ huynh vào quá trình học tập của con mình. Dù các bộ dữ liệu đều có mẫu nhỏ: ít nhất là 254 người trả lời [8] và nhiều nhất là 460 [7], nhưng các bộ dữ liệu này đều bổ sung các tài nguyên cần thiết để tạo tiền đề đánh giá về nhận thức và hành vi của sinh viên Việt Nam trong đợt dịch [4, $7,8]$, hay tác động của đại dịch tới của giảng viên $[5,6]$ tại Việt Nam.

Hiện nay, các tổ chức lớn như Our World in Data hay Open Development Mekong cũng công bố mở các bộ dữ liệu liên quan đến các ca bệnh tại Việt Nam cũng như các quốc gia khác. Cộng đồng khoa học thế giới đang kêu gọi sự minh bạch hóa trong dữ liệu khoa học ngày một mạnh mẽ hơn. Thậm chí, các quy trình thực hiện nghiên cứu hay quá trình phản biện cũng được đòi hỏi phải mở hơn nữa. Vì vậy, các đóng góp về dữ liệu này là cần thiết để kịp thời cung cấp thêm tài nguyên cho cộng đồng nghiên cứu xã hội, hưởng ứng minh bạch hóa khoa học tại Việt Nam.

Note: Đăng trên báo Khoa học và Phát triển tại URL: https://khoahocphattrien.vn/khoa-hoc/loat-bai-bao-mo-ta-du-lieu-ve-cac-vande-xa-hoi-trong-mua-dich-covid19-tu-vietnam/2020080706144617p1c160.htm

\section{References:}

[1] La, V. P., Pham, T. H. et al (2020). Policy Response, Social Media and Science Journalism for the Sustainability of the Public Health System Amid the COVID-19 Outbreak: The Vietnam Lessons. Sustainability. doi: 10.3390/su12072931 
[2] Huynh, T.L.D. (2020), The COVID-19 risk perception: A survey on socioeconomics and media attention. Economics Bulletin, 40(1), 758764.

[3] Huynh, T. L. (2020) Data for understanding the risk perception of COVID-19 from Vietnamese sample. Data in Brief. doi: https://doi.org/10.1016/j.dib.2020.105530

[4] Nguyen, V. D., Pham, H. G., Nguyen, N. D (2020). Impact of the COVID-19 pandemic on perceptions and behaviors of university students in Vietnam. Data in Brief. doi: https://doi.org/10.1016/j.dib.2020.105880

[5] Hoang, A. D., Ta, N. T. et al (2020). Dataset of ex-pat teachers in Southeast Asia's intention to leave due to the COVID-19 pandemic. Data in Brief. doi: https://doi.org/10.1016/j.dib.2020.105913

[6] Vu, C. T., Hoang, A. D. et al (2020). Dataset of Vietnamese teachers' perspectives and perceived support during the COVID-19 pandemic. Data in Brief. doi: https://doi.org/10.1016/j.dib.2020.105788

[7] Tran, T., Hoang, A. D. et al (2020). Dataset of Vietnamese student's learning habits during COVID-19. Data in Brief. doi: https://doi.org/10.1016/i.dib.2020.105682

[8] Bui, T. H, Luong, D. H. et al (2020). Impact of female students' perceptions on behavioral intention to use video conferencing tools in COVID-19: Data of Vietnam. Data in Brief. doi: https://doi.org/10.1016/j.dib.2020.106142.

[9] Vuong QH. (2020). Reform retractions to make them more transparent. Nature 582(7811):149. doi:10.1038/d41586-020-01694-x

[10] Vuong QH (2018). The (ir)rational consideration of the cost of science in transition economies. Nature Human Behaviour 2(1): 5, https://doi.org/10.1038/s41562-017-0281-4. 
